\title{
Vertical coupling of atmospheres: dependence on strength of sudden stratospheric warming and solar activity
}

\author{
Fazlul I Laskar ${ }^{1,2^{*}}$, Duggirala Pallamraju ${ }^{1}$ and Bhaskara Veenadhari ${ }^{3}$
}

\begin{abstract}
Comprehensive behavior of the low-latitude upper atmosphere during sudden stratospheric warming (SSW) events at varying levels of solar activity has been investigated. The equatorial electrojet (EEJ) strength and the total electron content (TEC) data from low latitudes over Indian longitudes during the mid-winter season in the years 2005 to 2013 are used in this study. Five major and three minor SSW events occurred in the observation duration, wherein the solar activity had varied from minimum (almost no sunspots) to mini-maximum (approximately 50 sunspots of the solar cycle 24). Spectral powers of the large-scale planetary wave (PW) features in the EEJ and the TEC have been found to be varying with solar activity and SSW strengths. Specially, the spectral powers of quasi-16-day wave variations during the three very strong SSW events in the years 2006, 2009, and 2013 were found to be very high in comparison with those of other years. For these major events, the amplitudes of the semi-diurnal tides and quasi-16-day waves were found to be highly correlated and were maximum around the peak of SSW, suggesting a strong interaction between the two waves. However, this correlation was poor and the quasi-16-day spectral power was low for the minor events. A strong coupling of atmospheres was noted during a relatively high solar activity epoch of 2013 SSW, which was, however, explained to be due to the occurrence of a strong SSW event. These results suggest that the vertical coupling of atmospheres is stronger during strong major SSW events and these events play an important role in enabling the coupling even during high solar activity.
\end{abstract}

Keywords: Sudden stratospheric warming; Planetary waves; Atmospheric tides; Total electron content; Sun-Earth interaction; Vertical coupling; Upper atmosphere; lonosphere; Thermosphere

\section{Background}

The low-latitude upper atmosphere of the Earth is coupled vertically to the lower atmospheric and horizontally to the high-latitude dynamical processes. While the neutral motions are affected via waves in the atmosphere and incoming solar radiation, the plasma motions are driven by the electrodynamical processes. Since both plasma and neutral species share the same space, their motions are coupled to each other in the upper atmosphere. Waves generated in the lower atmosphere propagate to the upper atmosphere under favorable background conditions (Shiokawa et al. 2009) and influence it by

\footnotetext{
* Correspondence: fazlul84@gmail.com

'Space and Atmospheric Sciences Division, Physical Research Laboratory, Ahmedabad 380009, India

${ }^{2}$ Indian Institute of Technology, Gandhinagar 382424, India

Full list of author information is available at the end of the article
}

altering the conductivities of the E-region, which, in turn, modulate the F-region processes, especially, over the low and equatorial latitudes, where the magnetic field lines are nearly horizontal.

Direct propagation of large-scale planetary wave (PW) (periods in the range of 2 to 30 days) oscillations which are mainly generated in the troposphere into the upper atmosphere is highly improbable (Pancheva and Mukhtarov 2012). However, it is believed that they can influence the upper atmosphere by modulating the shorter period gravity waves and tides (Lastovicka 2006). The gravity waves and tides with greater horizontal wavelengths are allowed to propagate to the upper atmosphere under suitable conditions, thereby enabling communication of the largescale lower atmospheric waves into the upper atmosphere. During sudden stratospheric warming (SSW) events, the PW amplitudes get amplified and the stratospheric and 
mesospheric zonal winds are also altered drastically rendering the conditions conducive for the propagation of the small-scale waves which are already modulated by the PWs (Liu et al. 2010; Yiğit and Medvedev 2012).

Even though the SSW is a northern hemispheric wintertime polar latitude phenomenon, the whole atmosphere of the Earth responds to these large-scale meteorological events (e.g., Fuller-Rowell et al. 2011). It is believed that the SSWs are produced by the wintertime vertical propagation of the tropospheric quasi-stationary PWs into the stratosphere and their interaction with the zonal mean flow, resulting in the dissipation of the waves in the stratosphere (Matsuno 1971). Due to this dissipation, energy and momentum are deposited in the stratosphere which modify the usual wintertime eastward zonal wind and enhance the stratospheric temperature. According to the World Meteorological Organization, if the stratospheric (at an altitude of $10-\mathrm{hPa}$ pressure level) temperature at northern polar latitudes (poleward of $60^{\circ} \mathrm{N}$ ) increases by more than $25 \mathrm{~K}$ within a week, then it is called an SSW event, and these temperature enhancements are considered as a good tracer of the planetary wave activity in the stratosphere. If in addition to the increase in temperature the usual wintertime eastward zonal mean zonal wind at $10 \mathrm{hPa}$ and at $60^{\circ}$ $\mathrm{N}$ reverses its direction, then the event is called major or else minor (Andrews et al. 1987). During SSW events, the interaction between enhanced planetary waves and tides and the interaction between tides and modified middle atmosphere modulate the tidal components, which register their signature in the upper atmospheric parameters (Jin et al. 2012; Pedatella and Liu 2013; Guharay et al. 2014). Also, nonlinear interaction between PWs and tides produces additional waves at the sum and the difference frequencies of the two original waves (Teitelbaum and Vial 1991) which fall mainly in the tidal domain.

By using datasets, such as the stratospheric wind, equatorial electrojet (EEJ) strength, total electron content (TEC), and multiwavelength dayglow intensities which originate from different altitudes of the atmosphere, it has been shown that the PW influence on the upper atmosphere is solar activity dependent (Laskar et al. 2013). That study motivated the present investigations using lowlatitude datasets at varying levels of SSW strengths and of solar activity (minimum to maximum). Clear signatures of the interaction between enhanced PWs and tides during SSW and the resulting influence on the upper atmospheric EEJ strength and TEC values are presented to demonstrate the vertical coupling of atmospheres and its dependence on solar activity and planetary wave activity in the lower atmosphere.

\section{Methods}

To obtain information on the low-latitude coupled ionosphere-thermosphere system during SSW and at different levels of solar activity, the EEJ strength and TEC data are used in this study.

\section{EEJ strength}

The horizontal component of geomagnetic field $(H)$ data is collected by magnetometers at an equatorial station, Tirunelveli (TIR) $\left(8.7^{\circ} \mathrm{N}, 77.7^{\circ} \mathrm{E} ; 0.1^{\circ} \mathrm{N}\right.$, magnetic latitude (MLAT)), and an off-equatorial station, Alibag (ABG) $\left(18.6^{\circ} \mathrm{N}, 72.9^{\circ} \mathrm{E} ; 10.3^{\circ} \mathrm{N}\right.$ MLAT). The anomalies in $H$ relative to its nighttime values at Alibag $\left(\Delta H_{\mathrm{ABG}}\right)$ are subtracted from the corresponding values at Tirunelveli $\left(\Delta H_{\mathrm{TIR}}\right)$, i.e., $\Delta H_{\mathrm{TIR}}-\Delta H_{\mathrm{ABG}}$, to obtain a measure on the EEJ strengths. The filled triangles in Figure 1 represent the locations from where magnetic measurements have been obtained.

\section{TEC}

The TEC data has been obtained from a southern hemispheric station, Diego Garcia $\left(7.27^{\circ} \mathrm{S}, 72.4^{\circ} \mathrm{E} ; 15.3^{\circ} \mathrm{S}\right.$ MLAT), that is located approximately in the same longitude sector as that used for obtaining the EEJ strength. The filled circle in the map of Figure 1 represents the location of the Global Positioning System (GPS) receiver. The solid line in Figure 1 represents the geomagnetic equator (according to the IGRF-2010 magnetic field model), and the two dashed lines parallel to it are the $\pm 15^{\circ}$ latitudes, which represent the approximate locations of the crest regions of the equatorial ionization anomaly (EIA). One may note that the Diego Garcia station falls approximately under the southern crest of the EIA. The receiver independent exchange (RINEX) format International GNSS Service (IGS) (Dow et al. 2009) data are processed using open-source GPS ToolKit (GPSTk) (Harris and Mach 2007; Laskar et al. 2013). While calculating vertical TEC values, satellites with elevation angles greater than $50^{\circ}$ are considered, which remove the dependence of TEC on ionospheric pierce point height and latitude, in addition to multipath effect in the low latitudes (Rama Rao et al. 2006; Bagiya et al. 2009).

\section{High-latitude stratospheric temperature}

The National Centers for Environmental Prediction (NCEP) and National Center for Atmospheric Research (NCAR) have cooperated in a project called reanalysis in which the temperature and wind are recovered from land surface, ship, rawinsonde, pilot balloon, aircraft, satellite, and other data (Kalnay et al. 1996). Daily averaged data at a $2.5^{\circ} \times 2.5^{\circ}$ grid for the whole globe and for 17 pressure levels from the Earth's surface up to $10 \mathrm{hPa}$ for several atmospheric parameters are made available. In this study, the stratospheric temperature at $10 \mathrm{hPa}$ (approximately $30 \mathrm{~km}$ ) from $90^{\circ} \mathrm{N}$ is used to obtain the temperature anomaly. From the NCEP/NCAR zonal mean zonal wind, it can be seen that three minor and 


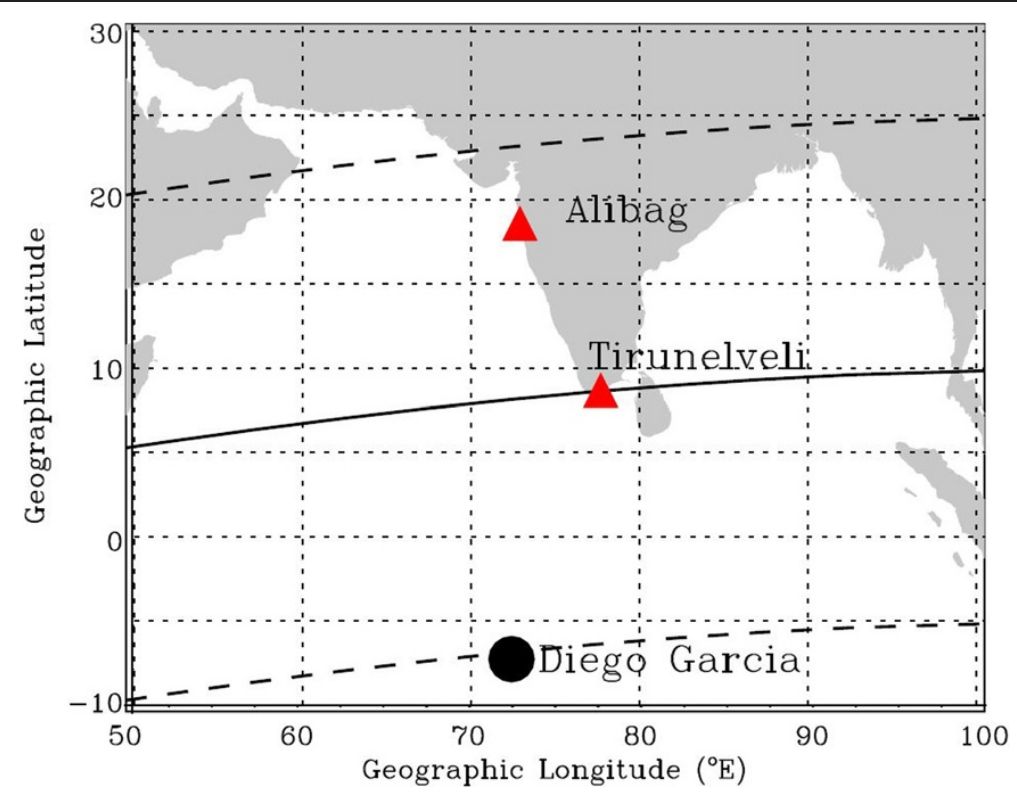

Figure 1 The geo-locations of the stations are depicted in the regional map in Indian longitudes. It may be noted that the GPS station (circle) and the EEJ derivation stations (triangles) are nearly at the same longitude sector. The dashed curves represent the $\pm 15^{\circ}$ latitudes, i.e., the approximate positions of the crest regions of the equatorial ionization anomaly.

five major warming events occurred during the years 2005 to 2013 (excluding those in the year 2008, wherein both major and minor events occurred one following the other). The nature of the SSW event and averaged sunspot number $(<\mathrm{SSN}>)$ during the observation period of January-February months in all the years are presented in Table 1. One can note that these events span solar activity levels with average SSN ranging from 0 to 51 .

\section{Analysis methodology}

The EEJ strength and TEC data during the JanuaryFebruary months in the years 2005 to 2013 are used in this study. In order to investigate the interaction between local-time-dependent waves and large-scale PWtype waves during SSW events, the following approach has been adopted. For each day, data are binned in hourly intervals, and then the data of a particular bin of every day are arranged to make a time series of 60 data points (for the 60 days) as shown in the left side panel (a) in Figure 2 for the EEJ strength data in the year 2006. Lomb-Scargle periodograms (Lomb 1976; Scargle 1982; Torrence and Compo 1998) of each of the time series in the left panel are shown in the right panel (b) in Figure 2. The plots are placed one below the other according to bins that are arranged by local time. Such analysis has the advantage that it reveals the local-time dependence, if any, of waves (such as solar tides of different periodicities and planetary-scale waves). One can note the presence of periods in 12 to 16 days, which are above the 90\% significance level, in these periodograms. Also, there is a systematic pattern in the PW-type periodicities of 12 to 16 days in the TEC and the EEJ, which is seen to be prominent throughout the daytime hours. Such method of determination of the dominant periods at different hours in the time series as shown in Figure $2 b$ for 2006 has been carried out for all the years (2005 to 2013) in

Table 1 Some of the atmospheric and solar parameters during the years 2005 to 2013

\begin{tabular}{lccccccccc}
\hline & \multicolumn{9}{c}{ Year } \\
\cline { 2 - 9 } & $\mathbf{2 0 0 5}$ & $\mathbf{2 0 0 6}$ & $\mathbf{2 0 0 7}$ & $\mathbf{2 0 0 8}$ & $\mathbf{2 0 0 9}$ & $\mathbf{2 0 1 0}$ & $\mathbf{2 0 1 1}$ & $\mathbf{2 0 1 2}$ & $\mathbf{2 0 1 3}$ \\
\hline$\Delta T_{\text {SSW }}$ & 40 & 60 & 40 & 60 & 60 & 40 & 35 & 30 & 45 \\
$T_{\text {peak_SSW }}$ & 240 & 260 & 245 & 268 & 265 & 237 & 235 & 245 & 248 \\
$U_{\text {east }}$ & +10 & -25 & -8 & -15 & -35 & -6 & +25 & +5 & -12 \\
SSW str. & Minor & Major & Major & Major & Major & Major & Minor & Minor & Major \\
$<$ SSN $>$ & 30 & 10 & 14 & 3 & 1 & 16 & 24 & 46 & 51 \\
\hline
\end{tabular}

$\Delta T_{\text {SSW, }}$ stratospheric temperature anomaly at $90^{\circ} \mathrm{N} ; T_{\text {peak_ssw, }}$ peak stratospheric temperature during SSW at $90^{\circ} \mathrm{N} ; U_{\text {east, }}$ peak eastward zonal mean stratospheric wind at $60^{\circ} \mathrm{N}$ during SSW; SSW str., SSW strength; $\langle\mathrm{SSN}\rangle$, average SSN. 


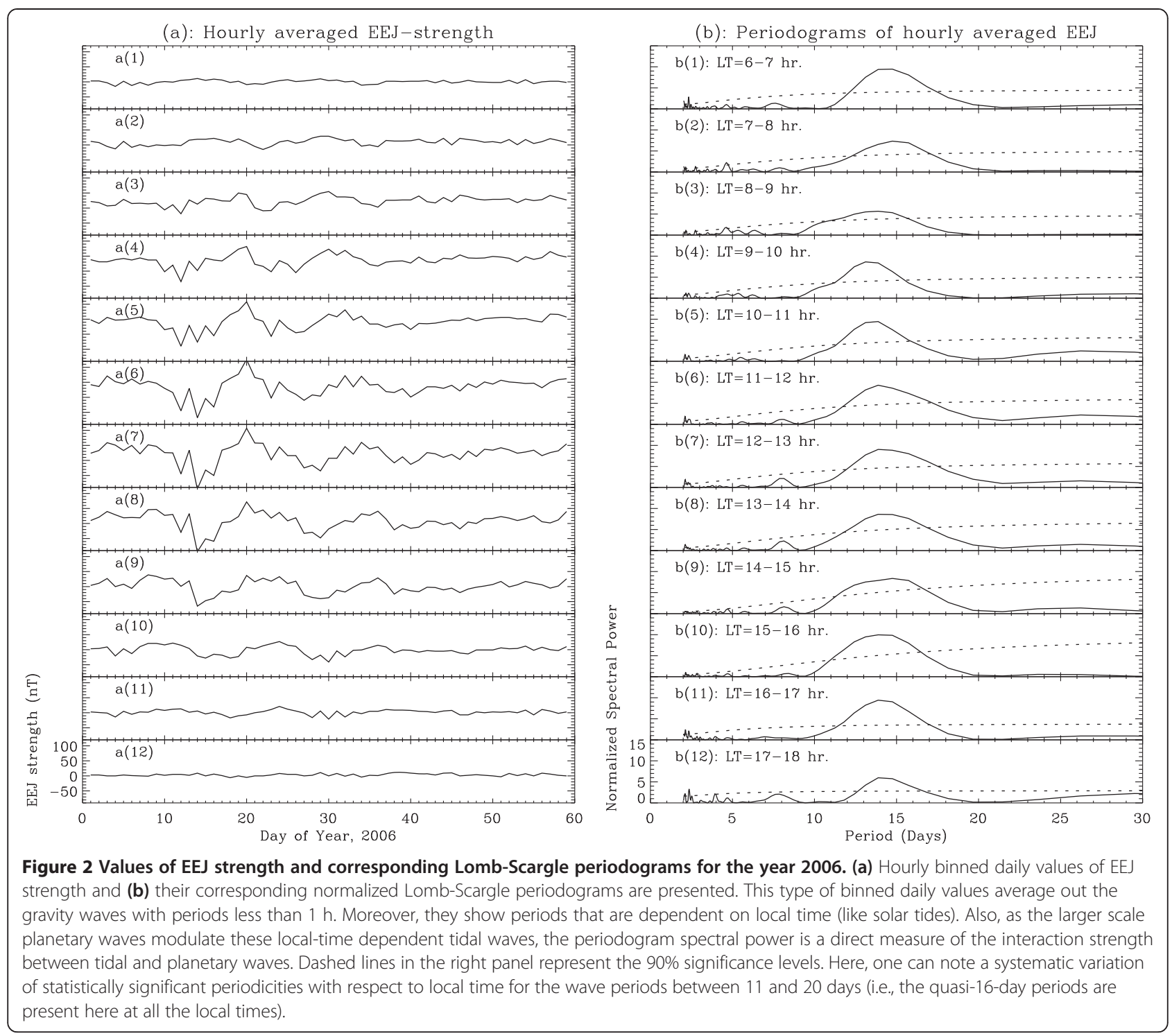

both the observed parameters, namely the EEJ and the TEC. The details of these periods and their dependence on SSW strength and solar activity level are described in the next section. As both major and minor events occurred in the year 2008 one after the other in quick succession, the events in this year have not been considered in the current analysis. Moreover, the TEC data also do not exist for this year.

\section{Results and discussion}

The low-latitude ionospheric dynamics is governed dominantly by the dynamo electric field of the E-region of the ionosphere. The off-equatorial E-region electric field $(E)$ maps over to the magnetic equator at the lower F-region altitudes. Under the influence of this $E$ field and the magnetic field $(B)$ of the Earth, the F-region plasma over the magnetic equator moves upward due to
$E \times B$ drift. This plasma then diffuses along the magnetic field lines and accumulates at around $\pm 15^{\circ}$ latitudes off the magnetic equator, building up regions of enhanced densities (crests) in plasma, and this phenomenon is known as the EIA (Raghavarao et al. 1988). The strength and latitude coverage of the EIA crest depends on season and lower atmospheric forcings of tidal nature (Immel et al. 2006; Pallamraju et al. 2004, 2010). Waves propagating from the lower atmosphere perturb the E-region dynamo electric field which is mapped to the F-region and thereby contribute to the redistribution of plasma. The amplitudes of these tidal waves are modulated at the lower atmosphere by the large-scale PWtype waves that are enhanced during SSW events. In addition to the shorter period dominant tidal waves, the normal-mode-type PW oscillations of 2, 5, 10, 16, and 25 days are generally observed in the upper atmosphere 
(e.g., Salby 1984; Sassi et al. 2012; Laskar et al. 2013). The EEJ strength which originates from around 105-km altitude region in the equatorial latitudes has been shown to be strongly modulated by lunar 14 to 15 day lunitidal period (Park et al. 2012). Here, in this study, the presence of waves in the PW regime (2 to 30 days) can be seen in Figure 2. The most dominant waves that have been observed in all these durations of observations are of the quasi-16-day type (11.2 to 20 days; Salby 1984). In some local time bins, the presence of 5- to 6-, 9- to 10-, and 27-day periods is also observed to be above the $90 \%$ significance level. However, the dominant mode present here is of quasi-16-day-type PWs which originate mainly in the lower atmosphere and are very sensitive to the stratospheric and mesospheric mean zonal winds (Luo et al. 2000). So, the large-scale waves and periodicities that appear in Figure 2 are believed to be associated with both variabilities of tides and PWs from the lower atmosphere.

A similar analysis, as that carried out for EEJ in the year 2006 as shown in Figure 2, has been carried out for all the years and in both the EEJ strength and the TEC data. For brevity, these periodograms have been converted into contour plots and all the periodograms at different local times have been normalized with their respective $90 \%$ significance level values and are shown in Figure 3. The left (a) and right (b) panels show the periodogram contours for the EEJ strength and the TEC from Diego Garcia. Each column represents data for 8 years from 2005 to 2013, wherein the $x$-axis represents the periods in days and the $y$-axis is the local time. The color bar represents the relative spectral powers compared to the strongest power in the year 2009 - the year of strongest SSW event of the past decade. This is done in order to compare the inter-year variation in powers for a given periodicity. Here, all the periods greater than the relative power of approximately 0.6 (dark green) are above $90 \%$ significance level. From this figure, one can note that the relative powers of the periods in the quasi16-day range are very prominent and are present in almost all the years presented here. The maxima of power at the quasi-16-day period range occur mostly at the same period range with respect to local time in the years 2006, 2007, and 2009 while for 2005, 2012, and 2013, one can note that the periods with maxima in power shift from shorter to longer periods from morning to evening. It is also notable that the periodicities in the EEJ and the TEC are, to a large extent, similar which is due to the fact that the low-latitude E-region electric field acts as a dominant driver for the plasma processes that eventually affect the F-region processes. Other than the quasi-16-day periods, one can see periodicities at 2, 5, 8 to 9, and 25 days in Figure 3. The 2- and 5-day waves are the normal mode oscillation of the lower atmosphere (Salby 1984). In addition to the Dopplershifted 10-day normal mode oscillation origin, the 8- to 9-day waves have also been reported to be related with the quasi-periodic variations of solar wind high-speed streams and recurrent geomagnetic activity, especially for the year 2005 (Thayer et al. 2008). Thus, some of the wave activities seen in these upper atmospheric parameters are due to both solar and lower atmospheric origin.

The average spectral power of the variations within the quasi-16-day range (11.5 to 20 days) and 6 to $18 \mathrm{~h}$ local time in the contour plots shown in Figure 3 are produced in Figure 4 for both the EEJ strength and the TEC. The letters ' $\mathrm{m}$ ' and ' $\mathrm{M}$ ' just above the $x$-axis stand for 'minor' and 'major' SSW events, respectively, that occurred during those observation windows. The dashed line ('+' symbol) in Figure 4 shows the northern polar latitude $\left(90^{\circ} \mathrm{N}\right)$ stratospheric temperature anomalies $(\Delta T)$ that occurred during the SSW events. The $\Delta T$ values are calculated by averaging the stratospheric temperature for a fairly stable duration prior to the occurrence of the SSW. In the absence of any index or parameter which represents the true strength of the SSW, this temperature anomaly is used as an indicator of the strength. It is expected that the $\Delta T$ values represent the stratospheric behavior in response to the SSW events. Strikingly, there are three maxima in both temperature anomaly and spectral powers of EEJ and TEC which occurred during the three strong major SSW years 2006, 2009, and 2013. Also, during the three minor warmings in the years 2005, 2011, and 2012, the spectral powers are comparatively low. These observations suggest that the strength of the SSW decides the spectral power of quasi-16-day waves in the upper atmospheric parameters. The quasi-16-day-type variations in the EEJ and ionospheric parameters are widely shown to be enhanced during SSW events (Pancheva et al. 2009). Notably, these three strong major events were the strongest of the major events in the last two decades. So, higher spectral power in these three major events implies that the stronger the SSW event, the stronger will be its effect on the low-latitude upper atmosphere. This happens because during major warmings the semi-diurnal tidal (both solar and lunar) and PW amplitudes are amplified and their combined action registers higher influence on the ionosphere (Stening et al. 1997; Pedatella and Liu 2013).

It can be noticed from Figure 3 that there are statistically significant quasi-16-day periods in all the years in addition to those in the three strong major warming years mentioned above. In spite of the fact that the SSWs in 2005, 2011, and 2012 were minor in nature, they showed appreciable amplitudes in the quasi-16-day power. Notably, these three minor events occurred during low solar activity epoch. Laskar et al. (2013) used 


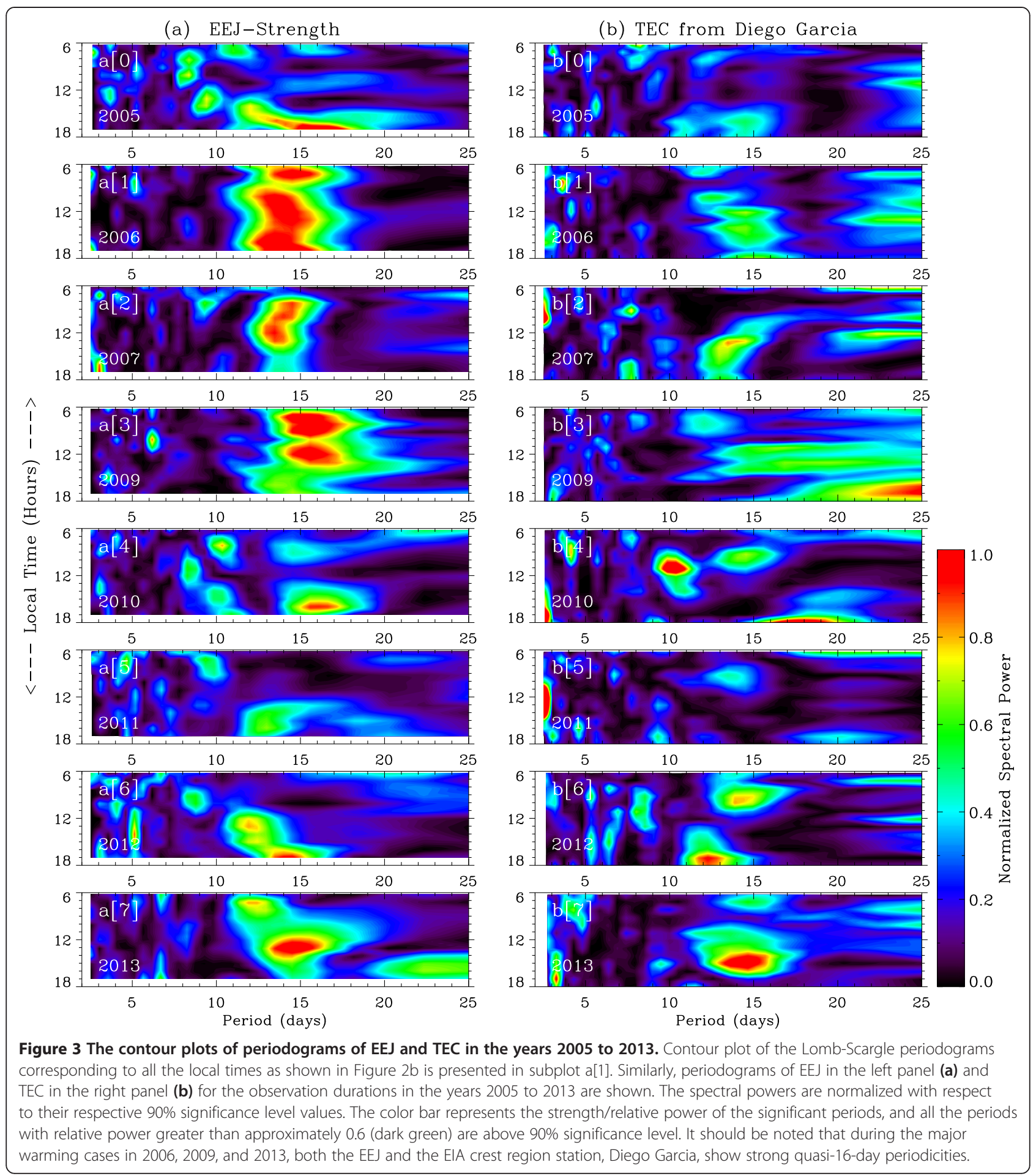

experimental observations to show that the coupling of lower and upper atmospheres is higher (lower) during low (high) solar activity. Such coupling in low solar activity is further enhanced when additional energy is available, such as that present during SSW events, which thus explains the appreciable amplitudes during these three minor events. Using numerical simulations, Pedatella and
Liu (2013) showed that for the same level of SSW activity, the lower atmospheric influence on the upper atmosphere is greater during low solar activity period in comparison to that at high solar activity, wherein solar influences dominate. Further, in the present case, one can note that the major SSW event in 2013, which occurred in relatively higher solar activity (average SSN of 51), shows strong 


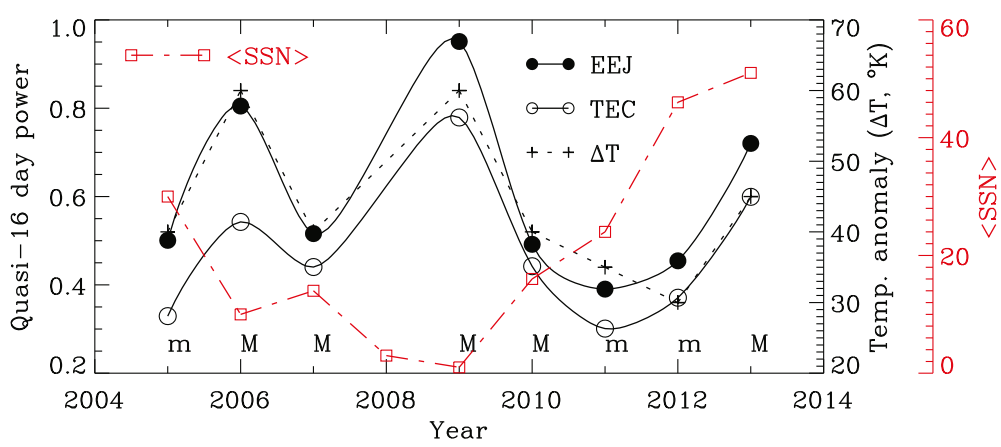

Figure 4 The mean normalized power of the quasi-16-day periodicities in EEJ strength and TEC. The power spectra as shown in Figure 3 are averaged between 11.5- and 20-day periods and for the whole day. The letters ' $\mathrm{m}$ ' and ' $\mathrm{M}$ ' represent 'minor' and 'major' SSW events, respectively, that occurred in the given year. The dashed curve shows the high-latitude stratospheric temperature anomaly $(\Delta T)$ on the peak of the SSW-related warming that represents the lower atmospheric behavior. One can note that the amplitudes have three peaks during the three strong major SSW events in the years 2006, 2009, and 2013 and three minima during the minor events in 2005, 2011, and 2012. It can be noted that there is a clear and systematic correspondence between the quasi-16-day amplitudes and the polar stratospheric temperature anomaly. The average SSN values are also shown with its axis at the right. It may also be noted that the relatively higher solar activity year 2013 showed a strong coupling due to increased lower atmospheric activity during strong SSW event.

amplitudes in the quasi-16-day periods. In our earlier study (Laskar et al. 2013), it was conjectured that even during high solar activity if there occurs a major SSW event, then it would provide additional energy which will significantly influence the upper atmosphere. In this work, the observation of the SSW event in 2013 is an experimental evidence to that conjecture. Support for this conjecture is also obtained from the published literature wherein the existence of perturbations in the ionosphere due to lower atmospheric forcings was reported during high solar activity in 2001 to 2004 and 2013, which actually occurred in simultaneity with major SSW events (e.g., Liu and Roble 2005; Pancheva et al. 2009; Fejer et al. 2010; Pedatella and Liu 2013; Goncharenko et al. 2013). These earlier reports have to be viewed in light of our conjecture that if the lower atmospheric forcing is stronger, as it happens during strong SSW events, then they can affect the upper atmosphere even during high solar activity periods. The current study demonstrates these features and places things in perspective with larger and independent datasets during low, moderate, and high solar activity epochs. The present study also reveals the plausible conditions in which an SSW event shows a greater effect on the upper atmosphere based on various waves and background dynamics as discussed below.

As mentioned above, the enhanced PWs and middle atmospheric dynamics during SSW modulate the tidal waves (mainly semi-diurnal) which further influence the ionosphere through the electrodynamical processes. To study the behavior of these waves, the relative variation in amplitudes of quasi-16-day and semi-diurnal waves had been looked into. Figure 5 shows the amplitudes of the semidiurnal (SD; thin continuous lines), an estimate of the $\mathrm{SD}$ envelope ( $\mathrm{SD}_{\text {envelope; }}$ thick continuous lines), and quasi-16-day (dashed) periodic variations in EEJ strength during the years of the current study. These amplitudes are obtained using the wavelet-based spectral analysis technique (Torrence and Compo 1998; Zaourar et al. 2013). It is known from the wavelet theory that the amplitudes of the harmonic components, like tides and PWs, can be obtained from the absolute value of the wavelet transform of the time series with the Morlet function as mother wavelet. The Morlet mother wavelet is best suited for studies of sinusoidal-type geophysical waves. The details of wavelet-based spectral analysis can be found in Torrence and Compo (1998). Both the semi-diurnal and quasi-16-day amplitudes appearing in Figure 5 are derived from the wavelet transform of the hourly values of the EEJ strength data. Interestingly, one may note from Figure 5 that the amplitudes of both semi-diurnal tides and quasi-16-day amplitudes are high and broadly vary in a similar fashion (as if semi-diurnal tides are modulated by the quasi-16-day waves) around the peak of SSW event, especially for the three strong major SSW events in 2006, 2009, and 2013.

As semi-diurnal oscillations are of higher frequency than those of planetary-scale waves in order to enable quantification of the correlation between SD variations and quasi16-day waves, an envelope of semi-diurnal amplitude, $\mathrm{SD}_{\text {envelope, }}$ values are derived. These $\mathrm{SD}_{\text {envelope }}$ values are obtained by a two-point smoothing of the curve joining the maxima of the 3-day (72 h) smoothed semi-diurnal amplitudes. One can note from Figure 5 that $\mathrm{SD}_{\text {envelope }}$ fairly follows the SD maximum amplitudes. The crosscorrelation coefficients $(R)$ between $\mathrm{SD}_{\text {envelope }}$ and quasi16-day amplitudes are also shown within the plots. One can note that for the three strong major SSW years 2006, 2009, and 2013, the correlation coefficient values are 0.78 , 


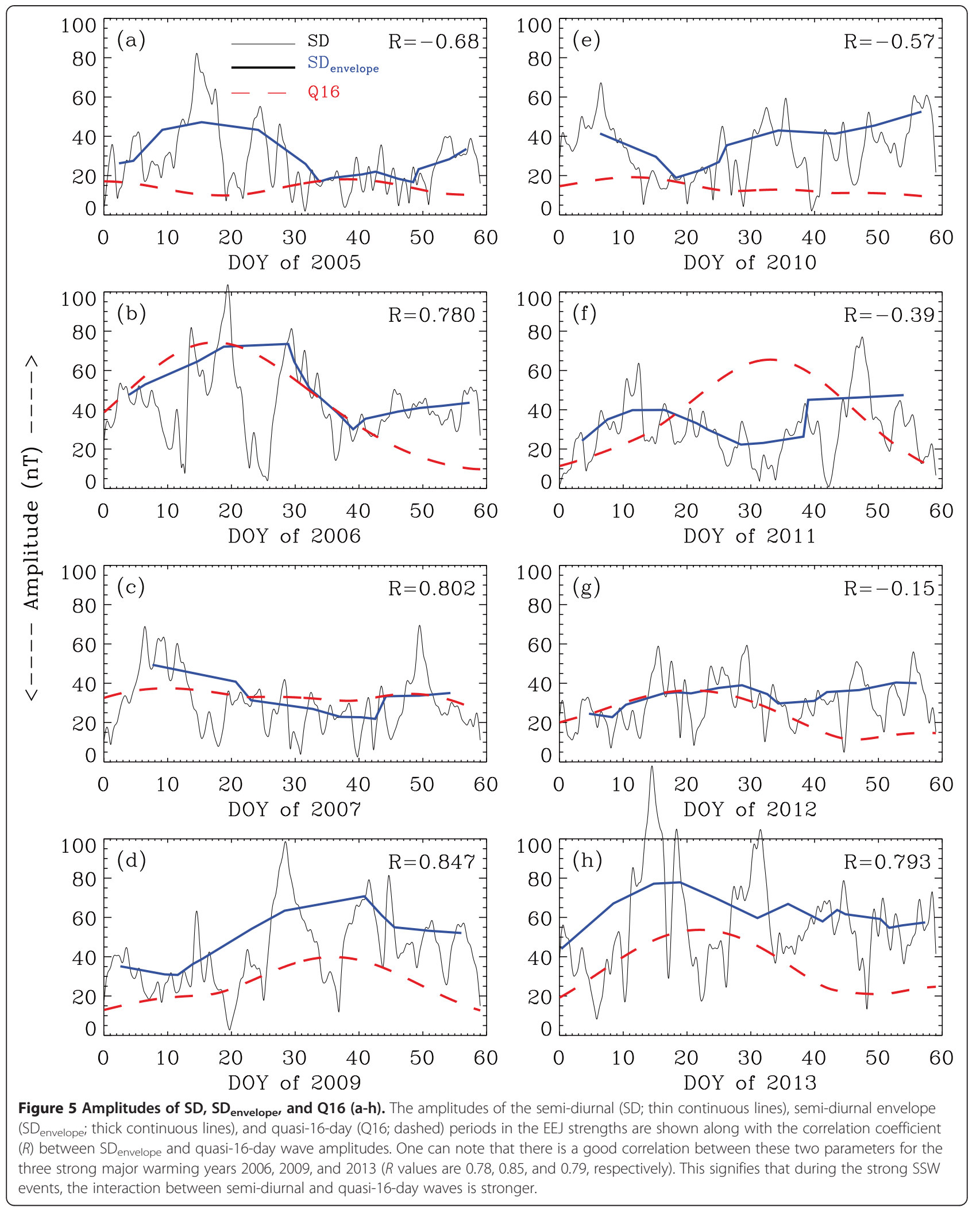


0.85 , and 0.79 , respectively. For the less major and the minor events, the correlation coefficients are negative (except for 2007, which was a late winter SSW event), which may possibly be due to the interaction of tides with some other PWs or with middle atmospheric dynamics (Jin et al. 2012). From these results, the plausible conclusion that can be arrived at is that during the three strong major SSW events in 2006, 2009, and 2013, there were strong interactions between semi-diurnal tides and quasi-16-day waves. Further, recent modeling studies suggest that the middle atmospheric dynamics play a dominant role in coupling the lower atmosphere and upper atmosphere during SSW events (Jin et al. 2012; Pedatella and Liu 2013). This study thus provides experimental evidence to the conjecture proposed earlier and revealed new aspects of interactions on the vertical coupling of atmospheres. These new aspects call for a detailed modeling and simulation studies, which are beyond the scope of the present communication, and will be carried out in the future.

\section{Conclusions}

Using two independently measured upper atmospheric parameters, namely the EEJ and the TEC, the vertical coupling of atmospheres during SSW events at varying levels of solar activity has been investigated. Individual SSW events during the years 2005 to 2013 have been considered. There were three very strong events during 2006, 2009, and 2013 of which the first two occurred during the low solar activity epoch and the 2013 event occurred during the so-called maximum of the 24th solar cycle. The main findings of this work are summarized below:

1. The spectral powers of the quasi-16-day wave oscillations in the EEJ and the TEC (over the crest of the EIA) are found to vary in a similar fashion to the high-latitude stratospheric temperature anomaly. The quasi-16-day spectral powers were found to be strong during the three strong major warming cases in 2006, 2009, and 2013 and weaker during the minor warming events in 2005, 2011, and 2012, implying that the intenseness of the SSW event decides the strength of vertical coupling.

2. It is observed that for those major events for which the quasi-16-day amplitudes are high, the broad variations in the amplitudes of semi-diurnal tide and the quasi16-day amplitudes are quite similar. To first order, this suggests that there occurs a strong interaction between semi-diurnal tides and quasi-16-day planetary waves for the strong major SSW events. This interaction has been found to be weaker for less major and minor events.

3. Even though the 2013 event occurred during relatively high solar activity epoch, the powers in the quasi-16day period in both the EEJ and the TEC were significantly strong. This observation supports the Laskar et al. (2013) proposition that even during high solar activity if an SSW event occurs, then the upper atmosphere is influenced significantly by lower atmospheric forcings due to additional energy that becomes available for enabling the vertical coupling of atmospheres through the PWs and middle atmospheric dynamics.

To conclude, the vertical coupling of atmospheres in terms of the strength of spectral amplitude is found to be dependent on the strength of SSW, solar activity, and interaction between tides and planetary waves.

\section{Abbreviations}

EEJ: equatorial electrojet; EIA: equatorial ionization anomaly; GPS: Global Positioning System; GNSS: Global Navigation Satellite System;

IGRF: International Geomagnetic Reference Field; NCEP: National Centers for Environmental Prediction; PW: planetary wave; SD: semi-diurnal tides; SSN: sunspot number; SSW: sudden stratospheric warming; TEC: total electron content.

\section{Competing interests}

The authors declare that they have no competing interests.

\section{Authors' contributions}

FIL developed the data analysis methodology, interpreted the results, and drafted the manuscript. DP actively participated in the discussions on this work and provided time to time guidelines, suggestions, and improvements during the preparation of the results and the manuscript. BV collected and validated the EEJ datasets and provided comments to the manuscript. All authors have approved the final manuscript.

\section{Acknowledgements}

The RINEX format GPS observational and navigational data are obtained from the International GNSS Service (IGS) network available online at http:// sopac.ucsd.edu/cgi-bin/dbDataBySite.cgi. We are grateful to NOAA/OAR/ESRL PSD, Boulder, CO, USA, for the NCEP/NCAR Reanalysis data on the website http://www.esrl.noaa.gov/psd/. The sunspot number and other geomagnetic indices data are obtained from NASA OMNIWeb. This work is supported by the Department of Space, Government of India.

\section{Author details}

${ }^{1}$ Space and Atmospheric Sciences Division, Physical Research Laboratory, Ahmedabad 380009, India. ${ }^{2}$ Indian Institute of Technology, Gandhinagar 382424, India. Indian Institute of Geomagnetism, Navi-Mumbai 410218, India.

Received: 30 April 2014 Accepted: 7 August 2014

Published: 18 August 2014

\section{References}

Andrews DG, Holton JR, Leovy CB (1987) Middle Atmosphere Dynamics. Academic, San Diego, p 489

Bagiya MS, Joshi HP, Iyer KN, Aggarwal M, Ravindran S, Pathan BM (2009) TEC variations during low solar activity period (2005-2007) near the equatorial ionospheric anomaly crest region in India. Ann Geophys 27:1047-1057. doi:10.5194/angeo-27-1047-2009

Dow J, Neilan R, Rizos C (2009) The International GNSS Service in a changing landscape of global navigation satellite systems. J Geod 83:191-198. doi:10.1007/500190-008-0300-3

Fejer BG, Olson ME, Chau JL, Stolle C, Lühr H, Goncharenko LP, Yumoto K, Nagatsuma T (2010) Lunar-dependent equatorial ionospheric electrodynamic effects during sudden stratospheric warmings. J Geophys Res 115:A00G03. do: 10.1029/2010JA015273

Fuller-Rowell T, Akmaev R, Wu F, Fedrizzi M, Viereck RA, Wang H (2011) Did the January 2009 sudden stratospheric warming cool or warm the thermosphere? Geophys Res Lett 38:L18104. doi:10.1029/2011GL048985 
Goncharenko L, Chau JL, Condor P, Coster A, Benkevitch L (2013) lonospheric effects of sudden stratospheric warming during moderate-to-high solar activity: case study of January 2013. Geophys Res Lett 40:4982-4986. doi:10.1002/grl.50980

Guharay A, Batista P, Clemesha B (2014) On the variability of the seasonal scale oscillations over Cachoeira Paulista (22.7S, 45W). Brazil Earth Planets Sp 66(1):45. doi:10.1186/1880-5981-66-45

Harris R, Mach R (2007) The GPSTk: an open source GPS toolkit. GPS Solut 11:145-150. doi:10.1007/s10291-006-0043-7

Immel TJ, Sagawa E, England SL, Henderson SB, Hagan ME, Mende SB, Frey HU, Swenson CM, Paxton LJ (2006) Control of equatorial ionospheric morphology by atmospheric tides. Geophys Res Lett 33:L15108. doi:10.1029/ 2006GL026161

Jin H, Miyoshi Y, Pancheva D, Mukhtarov P, Fujiwara H, Shinagawa H (2012) Response of migrating tides to the stratospheric sudden warming in 2009 and their effects on the ionosphere studied by a whole atmosphereionosphere model GAIA with COSMIC and TIMED/SABER observations. J Geophys Res Space Physics 117:A10. doi:10.1029/2012JA017650

Kalnay E, Kanamitsu M, Kistler R, Collins W, Deaven D, Gandin L, Iredell M, Saha S, White G, Woollen J, Zhu Y, Chelliah M, Ebisuzaki W, Higgins W, Janowiak J, Mo KC, Ropelewski C, Wang J, Leetmaa A, Reynolds R, Jenne R, Joseph D (1996) The NCEP/NCAR 40-year reanalysis project. Bull Amer Meteorol Soc 77(3):437-471

Laskar Fl, Pallamraju D, Lakshmi TV, Reddy MA, Pathan BM, Chakrabarti S (2013) Investigations on vertical coupling of atmospheric regions using combined multiwavelength optical dayglow, magnetic, and radio measurements. Geophys Res Space Physics 118:4618-4627. doi:10.1002/jgra.50426

Lastovicka J (2006) Forcing of the ionosphere by waves from below. J Atmos Sol-Terr Phys 68:479-497

Liu H-L, Roble RG (2005) Dynamical coupling of the stratosphere and mesosphere in the 2002 Southern Hemisphere major stratospheric sudden warming. Geophys Res Lett 32:L13804. doi:10.1029/2005GL022939

Liu H-L, Wang W, Richmond AD, Roble RG (2010) lonospheric variability due to planetary waves and tides for solar minimum conditions. J Geophys Res 115: A00G01. doi:10.1029/2009JA015188

Lomb NR (1976) Least-squares frequency analysis of unequally spaced data. Astrophys Space Sci 39:447-462. doi:10.1007/BF00648343

Luo Y, Manson AH, Meek CE, Meyer CK, Forbes JM (2000) The quasi 16-day oscillations in the mesosphere and lower thermosphere at Saskatoon $\left(52^{\circ} \mathrm{N}\right.$, 107W), 1980-1996. J Geophys Res 105:2125-2138. doi:10.1029/1999JD900979

Matsuno T (1971) A dynamical model of the stratospheric sudden warming. J Atmos Sci 28(8):1479-1494. doi:10.1175/1520-0469(1971)028<1479:ADMOT $\mathrm{S}>2.0 . \mathrm{CO} ; 2$

Pallamraju D, Chakrabarti S, Valladares CE (2004) Magnetic storm-induced enhancement in neutral composition at low latitudes as inferred by $O\left({ }^{1} D\right)$ dayglow measurements from Chile. Ann Geophys 22(9):3241-3250. doi:10.5194/angeo-22-3241-2004

Pallamraju D, Das U, Chakrabarti S (2010) Short- and long-timescale thermospheric variability as observed from Ol $630.0 \mathrm{~nm}$ dayglow emissions from low latitudes. J Geophys Res 115:A06312

Pancheva D, Mukhtarov P (2012) Planetary wave coupling of the atmosphereionosphere system during the Northern winter of 2008/2009. Adv Space Res 50(9):1189-1203

Pancheva D, Mukhtarov P, Andonov B, Mitchell NJ, Forbes JM (2009) Planetary waves observed by TIMED/SABER in coupling the stratosphere-mesospherelower thermosphere during the winter of 2003/2004: part 2-altitude and latitude planetary wave structure. J Atmos Sol-Terr Phys 71(1):75-87

Park J, Lühr H, Kunze M, Fejer BG, Min KW (2012) Effect of sudden stratospheric warming on lunar tidal modulation of the equatorial electrojet. J Geophys Res 117:A03306. doi:10.1029/2011JA017351

Pedatella NM, Liu H-L (2013) The influence of atmospheric tide and planetary wave variability during sudden stratosphere warmings on the low latitude ionosphere. J Geophys Res Space Physics 118:5333-5347. doi:10.1002/ jgra.50492

Raghavarao R, Sridharan R, Sastri JH, Agashe W, Rao BCN, Rao PB, Somayajulu W (1988) The equatorial ionosphere. In: Liu CH, Belva E (ed) WITS handbook. World Ionosphere/Thermosphere Study, vol 1. SCOSTEP Secretariat, University of Illinois, Urbana, pp 48-93

Rama Rao PVS, Niranjan K, Prasad DSWD, Gopi Krishna S, Uma G (2006) On the validity of the ionospheric pierce point (IPP) altitude of $350 \mathrm{~km}$ in the Indian equatorial and low-latitude sector. Ann Geophys 24(8):2159-2168 doi:10.5194/angeo-24-2159-2006

Salby ML (1984) Survey of planetary-scale travelling waves: the state of theory and observations. Rev Geophys 22(2):209-236. doi:10.1029/RG022i002p00209

Sassi F, Garcia R, Hoppel K (2012) Large-scale Rossby normal modes during some recent northern hemisphere winters. J Atmos Sci 69(3):820-839

Scargle JD (1982) Studies in astronomical time series analysis. II - statistical aspects of spectral analysis of unevenly spaced data. Astrophys J 263:835-853

Shiokawa K, Otsuka Y, Ogawa T (2009) Propagation characteristics of nighttime mesospheric and thermospheric waves observed by optical mesosphere thermosphere imagers at middle and low latitudes. Earth Planets Sp 61 (4):479-491. doi:10.1186/BF03353165

Stening RJ, Forbes JM, Hagan ME, Richmond AD (1997) Experiments with lunar atmospheric tidal model. J Geophys Res 102:13465-13471. doi:10.1029/ 97JD00778

Teitelbaum H, Vial F (1991) On tidal variability induced by nonlinear interaction with planetary waves. J Geophys Res 96(A8):14169-14178. doi:10.1029/ 91JA01019

Thayer JP, Lei J, Forbes JM, Sutton EK, Nerem RS (2008) Thermospheric density oscillations due to periodic solar wind high-speed streams. J Geophys Res 113:A06307. doi:10.1029/2008JA013190

Torrence C, Compo GP (1998) A practical guide to wavelet analysis. Bull Am Meteorol Soc 79(1):61-78. doi:10.1175/1520-0477(1998)079<0061: APGTWA $>2.0 . \mathrm{CO} ; 2$

Yiğit E, Medvedev AS (2012) Gravity waves in the thermosphere during a sudden stratospheric warming. Geophys Res Lett 39:L21101. doi:10.1029/ 2012GL053812

Zaourar N, Hamoudi M, Mandea M, Balasis G, Holschneider M (2013) Waveletbased multiscale analysis of geomagnetic disturbance. Earth Planets Sp 65 (12):1525-1540. doi:10.5047/eps.2013.05.001

doi:10.1186/1880-5981-66-94

Cite this article as: Laskar et al:: Vertical coupling of atmospheres: dependence on strength of sudden stratospheric warming and solar activity. Earth, Planets and Space 2014 66:94

\section{Submit your manuscript to a SpringerOpen ${ }^{\odot}$ journal and benefit from:}

- Convenient online submission

Rigorous peer review

- Immediate publication on acceptance

- Open access: articles freely available online

- High visibility within the field

- Retaining the copyright to your article

Submit your next manuscript at $>$ springeropen.com 